\title{
Cognitive Ability and Career Attainment: The Moderating Effects of Early Career Success
}

\author{
George F. Dreher \\ Indiana University \\ Robert D. Bretz, Jr. \\ Cornell University
}

Working Paper \#90-10

\author{
Center for Advanced Human Resource Studies \\ New York State School of Industrial \& Labor Relations \\ Cornell University \\ 393 Ives Hall \\ Ithaca, New York 14851-0952 \\ (607) 255-2273
}

This paper has not undergone formal review or approval of the faculty of the ILR School. It is intended to make results of Center research, conferences, and projects available to others interested in human resource management in preliminary form to encourage discussion and suggestions. 


\begin{abstract}
Three explanations regarding the prediction that early career success will moderate the relationship between cognitive ability and career attainment are presented along with an empirical examination of this issue. Using longitudinal data provided for 156 managerial, professional, and technical employees, significant moderating effects for an age-graded index of early career success were observed. The relationships between two measures of cognitive ability and later career job level were stronger for individuals identified as below average with respect to early career success than for their above average counterparts. These results agree with the proposition that the acquisition of knowledge, skills, and information is particularly dependent upon cognitive ability for individuals competing without the advantages associated with early career signals of high potential.
\end{abstract}




\section{Cognitive Ability and Career Attainment: The Moderating Effects of Early Career Success}

Over 10 years ago Roberts, Hulin, and Rousseau (1978) described contemporary selection research in terms of its focus on justification rather than improvement. That is, they reasoned that little new knowledge regarding how to design selection systems was forthcoming while much attention continued to be focused on utility estimates and the positive returns that are available when prescriptions from the past are properly implemented. They recommended a change in the standard selection research paradigm by emphasizing the need to incorporate response-relevant environmental characteristics in studies of functional relationships between measures of individual differences and outcome measures. The purpose of this article is to provide arguments and empirical evidence supporting the call to include a particular class of variables (pertaining to early career experiences) in future studies of the cognitive ability - career attainment relationship. As

prescribed by the framework of Roberts et al. (1978), we investigate the moderating effects of early career success on this relationship.

In what follows, we present three explanations for our prediction that early career success will moderate the relationship between ability and career attainment. These explanations are drawn from two paradigms used in the study of organizations and lead to contradictory conclusions regarding the directionality of the moderating effects of early career success. 


\section{Psychological Perspective}

Ability should affect career success through its effect on the acquisition of jobrelated knowledge and skills and by modifying motivational states. As reviewed by Hunter (1986), theories of knowledge acquisition predict that cognitive ability affects job performance because it accounts for the pace and thoroughness with which individuals acquire information. These theories also recognize that cognitive ability scores predict performance because they capture the ability to prioritize and be innovative in novel situations (Hunter, 1986).

In addition to the role ability plays in the process of acquiring job-related knowledge, cognitive approaches to motivation treat ability as a determinant of expectancy perceptions (Lawler, 1973; Porter \& Lawler, 1968; Vroom, 1964). Valence-InstrumentalityExpectancy (VIE) theory holds that individuals will not engage in behaviors for which they are not capable of performing. Specifically, individuals must believe that they possess or can acquire the attributes required to succeed before they will exert effort. Ability and prior success experiences are necessary for developing strong expectancy beliefs which in turn account for the form and duration of behavior in future settings.

Many VIE models (e.g., Porter \& Lawler, 1968) predict an interaction between cognitive ability and motivational states when accounting for accomplishment. Ability translates into accomplishment only when individuals attempt to achieve. When motivation is high, ability should account for variability in performance and career attainment. Low levels of effort expenditure should dampen ability - achievement relationships. This orientation will predict that early career success will moderate the ability - achievement relationship due to its effect on expectancy perceptions. A representative summary of the 
related literature is captured by Pinder (1987). "Success experiences are necessary for developing strong expectancy beliefs, and for maintaining a positive self-concept about one's work - a feeling of competence, self-determination, and high self-esteem (p. 83)". Following this logic, the ability - achievement relationship should be higher among individuals experiencing more extensive early career success than among counterparts experiencing less extensive early career success.

\section{Sociological Perspective}

Structural theories in sociology (and internal labor market theories in economics) offer alternative explanations regarding the role of early career experiences in defining ability - achievement relationships (Doeringer \& Piore, 1971; Rosenbaum, 1984; Turner, 1960; Spilerman, 1977). While traditional psychological theories maintain that attainments are primarily a function of hard work, perseverance, and ability, structural theories posit that employing firms segment the work force into unique opportunity circumstances (Rosenbaum, 1984). This segmentation occurs early in the career life cycle with the firm sponsoring employees in the primary labor market. Sponsorship takes the form of investments in specialized training, coaching, and entry into important and informal social networks. These networks are thought of as repositories for valuable information that is often difficult to obtain through formal channels. Because senior managers have difficulty in inferring individual potential, early career histories are taken as signals of ability and promise. In Rosenbaum's (1984) study of career mobility and in observations of other corporations (e.g., Kanter, 1977), among individuals at the same job level, those achieving the level sooner (at a younger age) were more likely to receive subsequent promotions. 
This is consistent with the view that early career signals are used to make decisions about sponsorship and special attention.

Beyond the specification of the processes that result in differential levels of sponsorship, structural theories provide contradictory predictions regarding the moderating effects of early career success on ability - career attainment relationships. One view would suggest that because sponsored employees receive specialized training and socialization they do not need to display the same level of perseverance or utilize the abilities required of their less fortunate counterparts when attempting to acquire critical job knowledge, skills and information. That is, the acquisition of knowledge, skills and information is particularly dependent upon ability among individuals competing without the advantages of sponsorship. This view predicts that ability - attainment relationships will be lower among employees experiencing relatively high levels of early career success than among employees with less successful early career histories.

An alternative explanation is based on the observation that sponsorship and mentoring relationships lead to increased exposure and visibility to upper level decision makers. As summarized by Kram (1985) in her review of the mentoring process, the "exposure-and-visibility function involves assigning responsibilities that allow a lower-level manager to develop relationships with key figures in the organization who may judge his or her potential for further advancement" (p. 27). This creates the opportunity to display ability and competence to senior management. If early career success increases the likelihood of receiving attention from a mentor or sponsor, ability - attainment relationships may be particularly strong among early attainment employees. It is for this class of individuals that opportunity exists to display talent. 


\section{The Current Study}

In summary, three explanations leading to the prediction that early career success will moderate the ability - attainment relationship have been provided. A psychological orientation, focusing on cognitive approaches to motivation, and a sociological/structural theory, focusing on visibility and exposure, lead to similar predictions. Using these arguments, the relationship between ability and attainment will be stronger among individuals experiencing the highest degrees of early career success than among counterparts experiencing less early career success. However, the structural approach addressing differences in how knowledge, skills, and information are acquired between sponsored and non-sponsored individuals leads to the opposite conclusion. Here, ability plays a more central role in accounting for subsequent attainment among individuals not receiving special attention and sponsorship.

In the current study, the moderating effects of early career success on ability attainment relationships are examined using a sample of managerial, professional and technical employees of a large oil company. The directionality of any observed moderating effects can then be compared to the predictions originating from the competing psychological and sociological perspectives. These results will be useful in judging the appropriateness of the Roberts et al. (1978) call for a change in the standard selection research paradigm and will have implications for how selection systems are evaluated and designed. 


\section{Method}

\section{Sample, Setting, and Measures}

Using longitudinal data provided by a large national oil company, we constructed an analysis sample that allowed for the examination of the predicted moderator effects. The data base is historical in the sense that the company no longer collects or maintains current information on the employees originally tested in the mid 1960s. However, for the purposes of the current study, the data serve as a unique source of information. The testing program from which these data originate represents one company's effort to design and evaluate an Early Identification of Managerial Potential (EIMP) selection system. The EIMP program has received considerable descriptive and evaluative attention (e.g., Campbell, Dunnette, Lawler, \& Weick, 1970, pp. 165-176; Laurent, 1968; Sparks, 1983). The analyses for the current study were performed on a subsample drawn from data originally used by Dreher (1982) in a study of managerial turnover. All managerial, professional, and technical (MPT) employees who were given the EIMP battery in either 1964 or 1965 and were still employed by the company in $1979(\mathrm{~N}=156)$ were selected. While these employees all had less than two years of company service at the time of testing, they were heterogeneous with respect to age and initial job level assignments. In addition to employee age and scores on two cognitive ability tests, the data provided a continuous record of job level attainment. The design called for the construction of an age-graded index of early career success. This index represented the moderator variable used in the examination of relationships between the measures of cognitive ability (collected in 1964 and 1965) and the job grade attained in 1979 . 
The age-graded measure of early career success (ECS) was constructed to take into account age and early career job level attainment. The company maintained an official job level structure based on formal job evaluation techniques. MPT jobs were assigned to one of 11 levels. These were indexed for the current study and ranged in value from 10 to 20 . We selected the job level attained in 1969 (after controlling for age) as the index of early career success. This was accomplished by regressing the 1969 job level on employee age and using the resulting equation to calculate an expected job level. The final index was the difference between the actual level attained in 1969 and the predicted level. This index attempts to capture the ability signaling attributes described by Rosenbaum (1984, p.270). Also, using age to construct this index receives conceptual support from Lawrence (1984), in her study of implicit organization timetables.

The company utilized two standardized cognitive ability tests in the EIMP battery. Raw scores on the Miller Analogies Test (Buros, 1978) and the Richardson, Bellows, Henry Test of Non-Verbal Reasoning (Buros, 1972) were used in conducting the current analyses.

Standard moderated regression analyses were conducted. Job level attained in 1979 served as the dependent variable. Separate analyses were performed for each cognitive ability test by first regressing the dependent measure on ECS and then sequentially entering the cognitive ability score and finally the ability X ECS interaction term. Significant interaction effects were displayed by calculating subgroup correlations using a median split on ECS. 


\section{Results}

Table 1 shows the relationships between the two indices of cognitive ability and job level attained in 1979. Pearson product-moment correlations suggest relatively strong, positive relationships between later career job level and scores on the Miller's Analogies Test $(r=.36)$ and the Test of Non-Verbal Reasoning $(r=.44)$

\section{Insert Table 1 About Here}

Regression results indicate that early career success explains $35 \%$ of the variation observed in later career success. In separate regression equations, each cognitive ability test significantly accounted for additional variation in job level attained. The Miller's Analogies Test explained an additional $6 \%$ of the variance, while the Test of Non-Verbal Reasoning accounted for an additional $10 \%$ of the variance. The interaction terms (ECS X ability) also contributed to explaining variance in job level attained. The interaction between early career success and the Miller's Analogies Test accounted for an additional 7\% of the variance, while the interaction with the Test of Non-Verbal Reasoning accounted for an additional $5 \%$ of the variance. Regression results are presented in Table 2.

\section{Insert Table 2 About Here}

The sample was split into two groups to examine the directionality of the moderating effects. Table 3 shows that the relationships between cognitive ability and later 
career job level are stronger for the group identified as below average with regard to early career success.

For the Miller's Analogies Test, Pearson correlations were $.21(\mathrm{p}<.05)$ and $.46(\mathrm{p}$ $<.01)$ for the above average and below average groups respectively. For the Test of NonVerbal Reasoning, Pearson correlations were $.31(\mathrm{p}<.01)$ and $.50(\mathrm{p}<.01)$ for the above average and below average groups respectively.

Insert Table 3 About Here

\section{Discussion}

The data reported here offer a unique opportunity to study the relationships between early career success, cognitive ability, and later career job level attainment. Over a decade ago, Roberts, et al. (1978) argued for the need to incorporate response-relevant environmental characteristics in studies of functional relationships between measures of individual differences and outcome measures. This study responds to this call for research by examining how a particular class of variables that describe early career experiences moderates the relationship between cognitive ability and subsequent career attainment.

One possible explanation for the observed interaction effects is based upon the argument that individuals experiencing early career advancement are more likely than their less successful early career counterparts to be sponsored and provided with information and training that will enhance their career prospects. Specifically, the acquisition of knowledge, skills, and information is hypothesized to be particularly dependent upon ability for 
individuals not experiencing early career advancement and therefore competing without the advantages of sponsorship. Indeed, the information processing demands associated with competition without sponsorship may be particularly high. Thus, our results may resemble, at the level of the individual, the results reported in the validity generalization literature (Hunter, 1986). This literature provides evidence that cognitive ability - performance relationships are moderated by job complexity as defined in terms of the information processing demands associated with tasks.

This explanation, of course, is speculative. However, the arguments provided regarding the likely moderating effects of early career success on ability - career outcome relationships seem sufficiently convincing to encourage subsequent work on this topic. In particular, we suggest that future studies of ability - career attainment relationships explicitly address and incorporate measures of mentorship and sponsorship in their designs. The degree to which individuals do or do not receive special attention should serve to constrain or facilitate the display of cognitive ability. The constraining versus facilitating properties of situations are central to Schneider's (1978) predictions about ability-situation interactions. We are proposing that early career success acts as a moderator of the ability attainment relationship and that the existing literature fails to provide a test of this hypothesis. The failure is based upon existing studies that include samples that are heterogeneous (within samples) with respect to early career success. Thus, across samples, there is little opportunity to observe variability on this dimension. This creates a situation in which the moderator is not given a chance to reveal itself when we examine the variability of a distribution of validity coefficients. We are calling for longitudinal designs 
that hold the organization constant while treating variables such as early career success, sponsorship, and mentorship as moderators of the ability -attainment relationship.

Prediction systems, particularly for middle and senior level managerial and professional talent, are likely to be improved if individual difference measures and early career experiences are treated as both main effect and interactive terms in models of the career attainment process. This does not run counter to the conclusions reached in the validity generalization literature devoted to cognitive ability tests (Hunter, 1986; Schmidt \& Hunter, 1981; Schmidt, Pearlman, Hunter, \& Hirsh, 1985). In this literature, situational specificity is addressed at the level of the organization, job, time period, or other factors associated with the immediate work environment. Differences in early career experiences operate at the level of the individual and have not been examined in meta-analytic reviews of this literature.

In summary, we have provided theoretical arguments and empirical evidence supporting the prediction that early career experiences moderate ability - attainment relationships. This suggests that the selection research paradigm recommended by Roberts et al. (1978) deserves further attention and that improvements in selection system accuracy are possible. 


\section{References}

Buros, O. K. (Ed.) (1972). The seventh mental measurements yearbook. 1, 702-703.

Buros, O. K. (Ed.) (1978). The eight mental measurements yearbook. 1, 274-275.

Campbell, J. P., Dunnette, M. D., Lawler, E. E. (1970). Managerial behavior, performance, and effectiveness. New York: McGraw-Hill.

Doeringer, P., \& Piore, M. (1971). Internal labor markets and manpower analysis. Lexington, Mass.: Heath Lexington Books.

Dreher, G. F. (1982). The role of performance in the turnover process. Academy of Management Journal, 25, 137-147.

Hunter, J. E. (1986). Cognitive ability, cognitive aptitudes, job knowledge, and job performance. Journal of Vocational Behavior, 29, 340-362.

Kanter, R. M. (1977). Men and women of the corporation. New York: Basic Books.

Kram, K. E. (1985). Mentoring at work: Developmental relationships in organizational life. Glenview, Il.: Scott, Foresman and Company.

Laurent, H. (1968). Research on the identification of managerial potential. In J. A. Myers (Ed.), Predicting managerial success (pp. 1-34). Ann Arbor, Mich.: Foundation for Research on Human Behavior.

Lawler, E. E. (1973). Motivation in work organizations. Monterey, California: Brooks/Cole.

Lawrence, B. S. (1984). Age grading: The implicit organization timetable. Journal of Occupational Behavior, $\underline{5}, 23-35$. 
Pinder, C. C. (1987). Valence-instrumentality-expectancy theory. In R. M. Steers, \& L. W. Porter (Eds.), Motivation and work behavior (pp. 69-89). New York: McGraw-Hill.

Porter, L. W., \& Lawler, E. E. (1968). Managerial attitudes performance. Homewood, Illinois: Dorsey Press.

Roberts, K. H., Hulin, C. L., \& Rousseau, D. M. (1978). Developing an interdisciplinary science of organizations. San Francisco: Jossey-Bass Publishers.

Rosenbaum, J. E. (1984). Career mobility in a corporate hierarchy. New York: Academic Press, Inc.

Schmidt, F. L., \& Hunter, J. E. (1981). Employment testing: Old theories and new research findings. American Psychologist, $\underline{36}, 1128-1137$.

Schmidt, F. L., Hunter, J. E., Pearlman, K., \& Hirsh, H. R. (1985). Forty questions about validity generalization and meta-analysis. Personnel Psychology, 38, 697-798.

Schneider, B. (1978). Person-situation selection: A review of some ability-situation interaction research. Personnel Psychology, 31, 281-304.

Sparks, C. P. (1983). Paper and pencil measures of potential. In G. F. Dreher, \& P. R. Sackett (Eds.), Perspectives on employee staffing and selection (pp. 349-368). Homewood, Illinois: Richard D. Irwin, Inc.

Spilerman, S. (1977). Careers, labor market structure, and socioeconomic achievement. American Journal of Sociology, $\underline{83}, 551-593$.

Vroom, V. H. (1964). Work and motivation. New York: Wiley. 


\section{TABLE 1}

Relationships Between Cognitive Ability and Later Career Job Level ( $\mathrm{N}=156)$

\begin{tabular}{lcrc} 
Variable & Mean & S.D. & $\mathrm{r}$ \\
\hline Miller's analogies test & 47.72 & 15.71 & $.36^{* *}$ \\
Non-verbal reasoning test & 17.73 & 4.17 & $.44^{* *}$ \\
\hline
\end{tabular}

$* * \mathrm{p}<.01$ 
TABLE 2

Moderated Regression Results for Two Measures of Cognitive Ability ( $\mathrm{N}=156$ )

\begin{tabular}{|c|c|c|c|c|}
\hline \multirow[b]{2}{*}{ Variable } & \multicolumn{2}{|c|}{ Miller's Analogies } & \multicolumn{2}{|c|}{ Non-Verbal Reasoning } \\
\hline & $\mathrm{R}^{2}$ & $\mathbf{R}^{2}$ & $\mathrm{R}^{2}$ & $\mathbf{R}^{2}$ \\
\hline Early Career Success & .35 & & .35 & \\
\hline Cognitive Ability & .41 & $.06 * *$ & .45 & $.10 * *$ \\
\hline Success $\mathrm{x}$ Ability & .48 & $.07 * *$ & .50 & $.05 * *$ \\
\hline
\end{tabular}

$* * \mathrm{p}<.01$ 


\section{TABLE 3}

Relationships Between Cognitive Ability and Later Career Job Level as Moderated by Early Career Success (ECS)

\begin{tabular}{|c|c|c|c|c|c|c|}
\hline \multirow[b]{2}{*}{ Variable } & \multicolumn{3}{|c|}{$\begin{array}{l}\text { Above Average } \\
\text { ECS } \quad(\mathrm{N}=78)\end{array}$} & \multicolumn{3}{|c|}{$\begin{array}{l}\text { Below Average } \\
\text { ECS } \quad(N=78)\end{array}$} \\
\hline & Mean & S.D. & $\mathrm{r}$ & Mean & S.D. & $\mathrm{r}$ \\
\hline Miller's Analogies & 49.22 & 15.15 & $.21^{*}$ & 46.21 & 16.11 & $.46^{* *}$ \\
\hline Non-Verbal Reasoning & 18.32 & 3.80 & $.31 * *$ & 17.21 & 4.49 & $.50 * *$ \\
\hline
\end{tabular}

$* \mathrm{p}<.05$

$* * \mathrm{p}<.01$ 